\title{
Prevention of Pulmonary and Venous Thromboembolism Post Coronary Artery Bypass Graft Surgery - Literature Review
}

\author{
Mansour Jannati ${ }^{1}$, MD; Alireza Abdi Ardecani ${ }^{1}, M D$
}

DOI: 10.21470/1678-9741-2018-0345

\begin{abstract}
Objective: The current review evaluates recent literature on the different aspects of prophylaxis in postoperative pulmonary and venous thromboembolism and their main risk factors.

Methods: The literature survey was carried out based on the PubMed data using the keywords "coronary artery bypass graft" and "venous thromboembolism" as components of the search field title.

Results: Studies reported several risk factors for postoperative
\end{abstract}

thromboembolism including advanced age, postoperative immobilization, type of thromboprophylaxis, obesity, and location of the surgery.

Conclusion: According to the studies, tailored prophylaxis could be easily adapted to decrease the intensity and duration of postoperative thromboembolism in a patient with several disorders and comorbidities, especially in cardiovascular disease.

Keywords: Coronary Artery Bypass. Venous Thromboembolism. Comorbidity. Risk Factors. Postoperative Period.

\begin{tabular}{llll}
\hline Abbreviations, acronyms \& symbols & & \\
\hline ACCP & = American College of Chest Physicians & MI & = Myocardial infarction \\
ACS & Acute coronary syndrome & MRI & $=$ Magnetic resonance imaging \\
AF & $=$ Atrial fibrillation & NOACs & $=$ Non-vitamin K antagonists oral anticoagulants \\
CABG & $=$ Coronary artery bypass graft & PAD & $=$ Peripheral arterial disease \\
CAD & $=$ Coronary artery disease & PE & $=$ Pulmonary embolism \\
CDC & $=$ Centers for Disease Control and Prevention & PESI & $=$ Pulmonary embolism severity index \\
CHD & $=$ Coronary heart disease & RCT & = Randomized controlled trials \\
CUS & $=$ Compression ultrasonography & RR & $=$ Relative risk \\
CVD & $=$ Cardiovascular disease & RV & $=$ Right ventricular \\
DVT & $=$ Deep vein thrombosis & SPESI & $=$ Simplified pulmonary embolism severity index \\
HFS & $=$ Hip fracture surgery & THA & $=$ Total hip arthroplasty \\
HT & $=$ Hypertension & TIA & $=$ Transient ischemic attack \\
IL & $=$ Interleukin & TKA & $=$ Total knee arthroplasty \\
LMWH & $=$ Low-molecular-weight heparin & TTE & $=$ Transthoracic echocardiography \\
MCP & $=$ Monocyte chemotactic protein & UFH & $=$ Unfractionated heparin \\
MDCT & $=$ Multi-detector computed tomographic & VKAs & $=$ Vitamin K antagonists \\
METHRO & $=$ Melagatran for Thrombin Inhibition in Orthopaedic & VTE & $=$ Venous thromboembolism \\
& Surgery & & \\
\hline
\end{tabular}

'Department of Cardiovascular Surgery, Faghihi Hospital, Shiraz University of Medical Sciences, Shiraz, Iran.

This study was carried out at the Shiraz University of Medical Sciences, Shiraz, Iran.
Correspondence Address: Mansour Jannati

(iD) https://orcid.org/0000-0002-0908-2247

Faghihi Hospital, Shiraz University of Medical Sciences Shiraz

Department of Cardiovascular Surgery

Iran - Zip Code: 1346246876

E-mail: mansour.jannati@mail.com 


\section{INTRODUCTION}

Cardiovascular disease (CVD) consists of a variety of disorders affecting the vascular structure, including hypertension (HT), atherosclerosis, coagulopathies, coronary heart disease (CHD), myocardial infarction (MI), stroke, and venous thromboembolism $(\text { VTE })^{[1]}$. VTE comprises two related disorders, including deep vein thrombosis (DVT) and pulmonary embolism (PE) ${ }^{[2]}$, and it is considered as the third most common disease among lifethreatening disorders, such as $\mathrm{Ml}$ and stroke ${ }^{[3]}$.

Several manifestations have been determined as the most frequent risk factors of VTE, including old age, previous VTE, chronic heart failure, $\mathrm{MI}$, malignancy, thrombophilia, prolonged immobility, hip fracture, the existence of central catheters, estrogen treatment, major surgery, and trauma ${ }^{[3]}$.

It has been also shown that among all clinical predictors of VTE, old age, chronic heart failure, MI, major surgery, and trauma are more associated with $\mathrm{PE}$, whereas DVT is mainly related to malignancy and thrombophilia ${ }^{[3]}$. Due to the difficulty of PE diagnosis and treatment, the mortality rate of $P E$ is higher than of other CVDs, such as MII ${ }^{[4]}$.

In a global survey performed in 2015, it has been shown that there was a relative lack of public awareness about thrombosis overall, and especially about the symptoms and signs of DVT and PE. It also applies to estrogen-containing medications as a risk factor for $V T E^{[5]}$. Evidence showed that the prevalence of VTE significantly increases after spine surgery in patients with walking disability before operation, elastic stocking, HT, lumbar surgery, and diabetes ${ }^{[6]}$.

A full dose of anticoagulant therapies, including unfractionated heparin (UFH), UFH and low-molecular-weight heparin (LMWH) as parenteral anticoagulants, fondaparinux, orally active vitamin $\mathrm{K}$ antagonists (VKAs) and non-vitamin $\mathrm{K}$ antagonists oral anticoagulants (NOACs), or thrombolysis, is recommended for both acute and long-lasting VTE patients ${ }^{[7,8]}$. One of the promising drugs for prevention of recurrent unprovoked VTE is Aspirin, which has low cost, with a once-daily application without dose monitoring ${ }^{[9]}$. Further preclinical research is required to determine the role of different risk factors and mechanisms in thrombosis formation to develop novel anti-inflammatory treatments, reducing the incidence of VTE in postsurgical patients.

In this review, we aimed to define DVT as the most common cause of PE, the risk factors of VTE and its therapeutic strategies, the VTE and atherothrombosis relationship, the prophylaxis for VTE, and, moreover, to evaluate the efficacy of these prophylactic strategies in reducing VTE without increasing the risk of postcardiac surgery complications.

\section{Data Collection}

The literature survey was carried out based on the PubMed data using the keywords "coronary artery bypass graft (CABG)" and "venous thromboembolism" as components of the search field title. We found 95 articles, among which those that included the objectives of the search were selected. Articles in languages other than English, texts that were not complete articles, and those published before 1990 were excluded.

\section{VTE in Cardiac Surgery and CABG}

Cardiac surgeries are accompanied with many risk factors for DVT development, such as general anesthesia, long hospital stay, long duration of surgery, too many manipulations in vascular structures throughout the surgery, immobilization, and etc ${ }^{[10]}$. Risk factors for DVT in CABG patients include obesity, cardiac failure, advanced age, female gender, hyperlipidemia, smoking, pregnancy, and etc ${ }^{[11]}$. Subsequent to cardiac surgery, DVT may cause important complications $^{[6]}$. VTE and PE may lead to mortality following cardiac surgery, and they are the fifth most common reason of readmission to hospital after $\mathrm{CABG}^{[12]}$. However, in most patients, DVT remains undetected and its signs normally become apparent within a few weeks after surgery ${ }^{[11]}$. The incidence of PE following cardiac surgery is $0.5-3.9 \%{ }^{[11]}$, and the incidence of detection of DVT is $13 \%$ of cases who underwent cardiac surgery ${ }^{[13]}$.

\section{Common Approaches in PE Diagnosis}

Diagnostic tests including chest $\mathrm{X}$-ray and electrocardiogram are applied to detect PE in suspected patients ${ }^{[14-17]}$. Based on different clinical predisposing factors, various scales have been used to predict PE probability, including PE severity index (PESI) and simplified PESI (SPESI) ${ }^{[18]}$. But the application of D-dimer for PE confirmation has been reduced due to its high negative predictive value. Among these, imaging tests such as invasive pulmonary angiography theoretically are widely used as a gold standard for a timely diagnosis of PE. But the specificity and sensibility of the multi-detector computed tomographic (MDCT) angiography are more suitable for clinical practice ${ }^{[18,19]}$. The alternative for MDCT is the pulmonary perfusion/ventilator scintigraphy. The application of magnetic resonance imaging (MRI)-angiography is rare in clinical practice because of its low sensitivity and high inconclusive results in PE diagnosis ${ }^{[20]}$. One of the best methods in PE diagnosis, particularly at patient's bed, is the noninvasive transthoracic echocardiography (TTE), which has low cost and provides respectable information on the degree of pulmonary HT and the severity of right ventricular (RV) dysfunction ${ }^{[18]}$. In patients with hemodynamic instability, echocardiography has been applied as a valuable test, in which appears the RV dysfunction leading to immediate PE treatment and survival ${ }^{[19,20]}$.

\section{DVT as the Most Common Cause of PE}

DVT is considered as the origin of PE in a lower limb in most cases. It has been recommended to apply sequential noninvasive surveys for DVT in patients with suspected PE. Venous ultrasonography is mostly used for diagnosis of patients with proximal and symptomatic DVT than with asymptomatic distal and recurrent DVT[21].

Among different standards which have been recommended for DVT diagnosis, the lack of vein compressibility occurred by venous thrombosis and evaluated by compression ultrasonography (CUS) is considered as a common criterion with a $90 \%$ sensitivity and 95\% specificity for symptomatic DVT ${ }^{[22,23]}$. Detection of a proximal DVT in PE suspected patients is the main sign of anticoagulant therapy without doing additional tests ${ }^{[20]}$. 


\section{Surgery and Postsurgical Inflammation as Risk Factors of VTE and its Therapeutic Strategies}

It has been shown that surgery leads to an increase of the risk of VTE, including DVT and PE. However, morbidity and mortality rates of postsurgical VTE remain high all over the world, even with the contemporary therapeutic strategies, such as mechanical manipulation and pharmacological prophylaxis ${ }^{[24]}$.

A series of triad factors, known as Virchow's triad, have contributed to form venous thrombi, including endothelial dysfunction, low blood flow, and a hypercoagulable state when they occur at the same time ${ }^{[25,26]}$. Low activity or stasis in patients after surgery may cause venous thrombosis formation ${ }^{[25,26]}$. Another factor involved in thrombosis is inflammation, which leads to a hypercoagulable state and endothelial damage. Initiation of the inflammatory response has been attributed to the pro-inflammatory cytokines rising, also called cytokine "storm", after surgery, which provides a pro-thrombotic environment followed by several cellular processes, such as neutrophil extracellular traps formation, platelet activation, the tissue factorbearing micro-particles localization, and endothelial injury. In a research on the incidence of symptomatic VTE by type of surgery, White et al. found out that the percentage of incidence/case was high in orthopaedic (1.2\%) and vascular (1.1\%) surgeries ${ }^{[27]}$.

In a literature review of studies on the relevance of predisposing factors involved in VTE after total hip arthroplasty $(\mathrm{THA})^{[28]}$, several factors have been introduced, including the diagnosis of hip fracture ${ }^{[29]}$, malignancy ${ }^{[30]}$, particularly with chemotherapy, antiphospholipid syndrome ${ }^{[31]}$, immobility or reduced mobility ${ }^{[32]}$, history of $\mathrm{VTE}^{[33]}$, tamoxifen ${ }^{[34]}$ and raloxifene $^{[35]}$ therapy, estrogen replacement therapy, stroke ${ }^{[36]}$, atherosclerosis ${ }^{[37]}$, old age ${ }^{[38]}$, and obesity ${ }^{[28,39]}$. Other factors, such as diabetes mellitus ${ }^{[40]}$, certain cardiovascular conditions ${ }^{[30]}$, leukemia ${ }^{[41]}$, varicose veins, and smoking, presented low risk ${ }^{[28]}$. Findings of a systematic review and meta-analysis of different observational studies and randomized controlled trials (RCT) showed that some factors, such as previous history of VTE, obesity, left or right ventricular failure, prolonged bed rest, mechanical ventilation, or a central venous catheter application, are considered as common risk factors of VTE ${ }^{[42]}$.

Based on the 2012 American College of Chest Physicians (ACCP) guidelines on VTE prevention in orthopaedic surgery patients, the use of VTE prophylaxis, such as Aspirin, have been recommended in patients undergoing major orthopaedic surgeries, including THA, total knee arthroplasty (TKA), and hip fracture surgery (HFS) ${ }^{[43]}$. Prolonged low-dose Aspirin therapy has also been recommended by the ACCP guidelines for secondary prevention of coronary artery disease (CAD) events ${ }^{[44,45]}$. In a review by Cohen et al. ${ }^{[46]}$, Aspirin has been introduced as the key component in the management of CVD events, including secondary prevention of CAD and acute coronary syndrome (ACS), and non-cardioembolic stroke or transient ischemic attack (TIA), primary prevention of stroke in patients with low thrombotic risk of atrial fibrillation (AF), and primary and secondary prevention of peripheral arterial disease (PAD). In a study performed by Hawkins, the role of oral direct thrombin inhibitors in the VTE prevention was evaluated ${ }^{[47]}$. Ximelagatran, a new low-molecular-weight oral prodrug, has been introduced as the direct thrombin inhibitor melagatran of VTE in patients with orthopaedic surgery compared to warfarin or fondaparinux ${ }^{[47]}$. The safety and efficacy of melagatran and its prodrug ximelagatran in VTE prophylaxis have been established in several European trials of the Melagatran for Thrombin Inhibition in Orthopaedic Surgery (METHRO) ${ }^{[48,49]}$.

\section{What is the Association Between VTE and Atherothrombosis?}

It has been shown that VTE and atherothrombosis display the same pathophysiology of inflammation, hypercoagulability, endothelial injury, and cardiovascular risk factors, including obesity, $\mathrm{HT}$, diabetes mellitus, cigarette smoking, hypercholesterolemia, congestive heart failure, and metabolic syndrome ${ }^{[4]}$. Steffen et al. ${ }^{[50]}$ found out that there is a significant relationship between metabolic syndrome and risk of VTE in a survey of 20,374 patients.

One of the best-considered components in the VTE epidemiology is that pan-cardiovascular syndromes, including CAD, PAD, and CVD, are associated with VTE manifestation. Evidence evaluated that several medical conditions, such as immobility, heart failure, chronic lung disease, and chronic kidney disease, increase VTE risk in patients with symptomatic atherosclerotic CAD.

\section{Inflammation Markers and Risk Factors Involved in VTE}

Several markers have been attributed to VTE pathogenesis, including interleukin (IL)-6, IL-8, and monocyte chemotactic protein (MCP)- ${ }^{[51]}$. VTE risk factors were divided to inherited thrombophilias, including VTE in many family members, idiopathic or recurrent VTE, recurrent spontaneous abortions, factor $V$ Leiden, prothrombin gene mutation 20210, deficiencies of protein $C$, protein $S$, or antithrombin, and acquired risk factors, including old age, cancer, immobility, and recent trauma, surgery, or hospitalization ${ }^{[4,52]}$. Among different cancers, patients with stomach and pancreatic cancers are at high risks in developing VTE ${ }^{[53]}$. Other cancers, including lung, gynecologic, bladder, and testicular cancers, and lymphoma develop VTE with high incidence ${ }^{[53]}$. Middle-aged women are prone to develop VTE during the first 12 postoperative weeks ${ }^{[54]}$. Pregnancy, oral contraceptives containing estrogen, and hormone replacement are considered as important VTE risk factors in women ${ }^{[55]}$.

\section{VTE Management in Pregnancy}

It has been recommended that the same diagnostic and therapeutic strategy should be applied to pregnant patients ${ }^{[56]}$. The first step of diagnosis is real-time or duplex ultrasound, especially in iliofemoral DVTs, and then ultrasound or X-ray venogram is repeated ${ }^{[56]}$. In VTE suspected patients, a ventilation-perfusion lung scan is recommended. UFH or LMWH are applied for treatment, which should be maintained during the pregnancy and should be altered to warfarin postpartum for at least six weeks ${ }^{[57]}$. Another controlling approach in pregnant patients with VTE is a screening of thrombophilia ${ }^{[56]}$. 


\section{The Role of Prophylaxis in VTE Reduction Without Increasing the Risk of Complications After Cardiac Surgery}

One of the most important risk factors forVTE is hospitalization. Based on reports of the Centers for Disease Control and Prevention $(C D C)$, most hospitalizations are complicated by VTE, including DVT and PE, in patients with age $\geq 18$ years annually. In a systematic review and meta-analysis in 2015, data showed that VTE prophylaxis was significantly correlated with a reduced risk of PE (with relative risk [RR], 0.45; 95\% confidence interval) or symptomatic VTE (RR, 0.44) compared to the control group ${ }^{[42]}$. Any sign of bleeding or cardiac tamponade requiring reoperation due to pharmacological VTE prophylaxis without systemic anticoagulation therapy was not detected in patients undergoing cardiac surgery ${ }^{[42]}$.

\section{DISCUSSION}

For surgical procedures including cardiac surgeries, especially post $C A B G$, that are not correlated with any comorbidities, such as appendectomy and cholecystectomy, or with coexisting comorbidities, advancing age will be attributed as a significant cause and predictor of thromboembolism.

In a study by Ambrosetti et al ${ }^{[58]}$, a relatively high rate of DVT after CABG was shown (about 17\%). In their study, two of the 47 patients with DVT acquired PE, being fatal in one patient. Goldhaber et al. ${ }^{[59]}$ reported an approximately 22\% DVT rate after CABG. A study by Reis et al. ${ }^{[60]}$ revealed that the incidence of DVT after cardiac bypass surgery was $48.3 \%$, diagnosed at about 6.5 days after surgery. Viana et al. ${ }^{[64]}$ observed isolated DVT in $4 \%$ and simultaneous DVT in $8 \%$ of CABG patients.

Studies showed that PE occurred in 0.4 to $9.5 \%$ of patients after bypass surgery, and it was fatal in 0.3 to $1.7 \%$ of the cases ${ }^{[61,62]}$. Beck KS et al. showed that the PE rate after CABG was $6.2 \%$ and it mostly occurred at the segmental or subsegmental leve[|[63]. Viana et al. ${ }^{[64]}$ observed isolated PE in 13\% and simultaneous PE in $8 \%$ of CABG patients. In Goldhaber et al. ${ }^{[59]}$ study, the frequency of PE was $0.6 \%$ in patients with bypass and the rate of fatal massive PE was $0.3 \%$. In another study by Josa et al. ${ }^{[62]}$, the frequency of PE was $3.2 \%$ after cardiac surgery.

It is expected that the VTE incidence strongly associated with age remains and will be increased after cardiac surgery. Previous studies have reported that advancing age is related to postsurgical VTE ${ }^{[65,66]}$. Although VTE contributed as a main preventable factor of morbidity and mortality in hospitalized patients, controversy still exists on the efficacy and safety of VTE prophylaxis after cardiac surgery. Further research, in preclinical models, is required to determine the precise association of VTE prophylaxis and management of thrombosis. This may simplify the improvement of novel anti-inflammatory managements to decrease VTE occurrence in the postsurgical settings. In this regard, it is essential that physicians be aware of the proinflammatory mechanisms involved in thrombus formation in their patients.

The findings of this study are mainly based on the evidence available in previous and recent review studies ${ }^{[67,68]}$. With these evidences, we found out that VTE prophylaxis could reduce PE and symptomatic VTE risk in post-cardiac surgery without any bleeding and cardiac tamponade in patients.

Ho et al. ${ }^{[42]}$ reported that initiating pharmacological VTE prophylaxis soon after cardiac surgery for patients who have no active bleeding is highly recommended. Close et al. ${ }^{[69]}$ recommended that all patients after cardiac surgery initiate the use of heparin prophylaxis the day after their surgery and continue this up to discharge. Sarker et al. ${ }^{[70]}$ reported that combined treatment with rivaroxaban and heparin is effective in a case of post-CABG DVT patient.

In a study by Kulik et al. ${ }^{[1]}$ on the effectiveness of preventative therapy for VTE after CABG, they found out that the administration of chemical or mechanical preventative therapies to CABG patients does not appreciably lower the risk of VTE.

In line with a systematic review and meta-analysis study, some packages of evaluated VTE prophylaxis had sufficient safety and efficacy in PE and symptomatic VTE reduction ${ }^{[42]}$. However, they concluded that sufficient data did not exist regarding the efficacy of one type of VTE prophylaxis compared to other types or if a specific therapeutic agent was superior to the others ${ }^{[42]}$. In terms of VTE in hip arthroplasty, most conducted studies and their findings indicated that platelets play an important role in the VTE pathogenesis ${ }^{[71]}$. In a survey of 13,356 patients with hip fracture or undergoing hip arthroplasty, the efficacy of antiplatelet agents on first episode and recurrence of VTE was found ${ }^{[72]}$. In this regard, Aspirin has been recommended by different researchers as one of the most common drugs to prevent VTE after surgery, including CABG. On the other hand, Aspirin resistance is a common phenomenon observed in high doses during the first week after cardiac surgery ${ }^{[73]}$. A low dose of antiplatelet agents, such as Aspirin, has not been recommended by surgeons due to its weak function in VTE prevention in high-risk cardiac patients ${ }^{[73]}$. Application of Aspirin alternative, such as UFH or LMWH, offering additional VTE protection has not shown an increase in risks of bleeding, pericardial effusion, and cardiac tamponade ${ }^{[74]}$. In a cohort study, Kulik et al. ${ }^{[75]}$ reported that application of UFH or LMWH during 48 hours in post-CABG patients were not associated with bleeding risk compared to no VTE prophylaxis. A large quantity of evidence showed that bleeding could occur after overdose of anticoagulation therapy ${ }^{[67]}$.

Findings of the current study showed that there was an evidence gap regarding VTE and PE prevention, especially after $C A B G$, suggesting that it is essential to perform more RCT and cohort studies to evaluate the precise efficacy and safety of various anticoagulant agents in reducing VTE and their cost-effectiveness after cardiac surgery. In conclusion, the development of various therapeutic strategies and prophylaxis is needed to prevent PE and symptomatic VTE events after cardiac surgery.

\section{No financial support. \\ No conflict of interest.}




\section{Authors' roles \& responsibilities}

MJ Substantial contributions to the conception or design of the work; or the acquisition, analysis, or interpretation of data for the work; drafting the work or revising it critically for important intellectual content; final approval of the version to be published

AAA Substantial contributions to the conception or design of the work; or the acquisition, analysis, or interpretation of data for the work; drafting the work or revising it critically for important intellectual content; final approval of the version to be published

\section{REFERENCES}

1. Goldhaber SZ. Preventing pulmonary embolism and deep vein thrombosis: a'call to action'for vascular medicine specialists. JThromb Haemost. 2007;5(8):1607-9. doi:10.1111/j.1538-7836.2007.02651.x.

2. Imberti D, Ageno W, Manfredini R, Fabbian F, Salmi R, Duce R, et al. Interventional treatment of venous thromboembolism: a review. Thromb Res. 2012;129(4):418-25. doi:10.1016/j.thromres.2011.11.003.

3. Nielsen JD. The incidence of pulmonary embolism during deep vein thrombosis. Phlebology. 2013;28 Suppl 1:29-33. doi:10.1177/0268355513477009.

4. Goldhaber SZ. Venous thromboembolism: epidemiology and magnitude of the problem. Best Pract Res Clin Haematol. 2012;25(3):235-42. doi:10.1016/j.beha.2012.06.007.

5. Wendelboe AM, McCumber M, Hylek EM, Buller H, Weitz J, Raskob G. Global public awareness of venous thromboembolism. J Thromb Haemost. 2015;13(8):1365-71. doi:10.1111/jth.13031.

6. Wang T, Yang SD, Huang WZ, Liu FY, Wang H, Ding WY. Factors predicting venous thromboembolism after spine surgery. Medicine (Baltimore). 2016;95(52):e5776. doi:10.1097/MD.0000000000005776.

7. Potpara TS, Lip GY. Novel oral anticoagulants in non-valvular atrial fibrillation. Best Pract Res Clin Haematol. 2013;26(2):115-29. doi:10.1016/j. beha.2013.07.008.

8. Mekaj YH, Mekaj AY, Duci SB, Miftari El. New oral anticoagulants: their advantages and disadvantages compared with vitamin Kantagonists in the prevention and treatment of patients with thromboembolic events. Ther Clin Risk Manag. 2015;11:967-77. doi:10.2147/TCRM.S84210.

9. Mekaj YH, Daci FT, Mekaj AY. New insights into the mechanisms of action of aspirin and its use in the prevention and treatment of arterial and venous thromboembolism. Ther Clin Risk Manag. 2015;11:1449-56. doi:10.2147/TCRM.S92222.

10. Labropoulos N, Bishawi M, Gasparis A, Tassiopoulos A, Gupta S. Great saphenous vein stump thrombosis after harvesting for coronary artery bypass graft surgery. Phlebology. 2014;29(4):215-9. doi:10.1258/ phleb.2012.012094.

11. Kulik A, Rassen JA, Myers J, Schneeweiss S, Gagne J, Polinski $J M$, et al. Comparative effectiveness of preventative therapy for venous thromboembolism after coronary artery bypass graft surgery. Circ Cardiovasc Interv. 2012;5(4):590-6. doi:10.1161/ CIRCINTERVENTIONS.112.968313.

12. Shammas NW. Pulmonary embolus after coronary artery bypass surgery: a review of the literature. Clin Cardiol. 2000;23(9):637-44. doi:10.1002/ clc.4960230903.

13. Schwann TA, Kistler L, Engoren MC, Habib RH. Incidence and predictors of postoperative deep vein thrombosis in cardiac surgery in the era of aggressive thromboprophylaxis. Ann Thorac Surg. 2010;90(3):760-6; discussion 766-8. doi:10.1016/j.athoracsur.2010.03.117.

14. Musset D, Parent F, Meyer G, Maître S, Girard P, Leroyer C, et al. Diagnostic strategy for patients with suspected pulmonary embolism: a prospective multicentre outcome study. Lancet. 2002;360(9349):191420. doi:10.1016/S0140-6736(02)11914-3.

15. Le Gal G, Righini M, Roy PM, Sanchez O, Aujesky D, Bounameaux H, et al. Prediction of pulmonary embolism in the emergency department: the revised Geneva score. Ann Intern Med. 2006;144(3):165-71. doi:10.1016/j. jemermed.2006.05.013.

16. Kearon C, Akl EA, Ornelas J, Blaivas A, Jimenez D, Bounameaux H, et al. Antithrombotic therapy for VTE disease: CHEST guideline and expert panel report. Chest. 2016;149(2):315-52. Erratum in: Chest. 2016;150(4):988. doi:10.1016/j.chest.2015.11.026.

17. Ceriani E, Combescure C, Le Gal G, Nendaz M, Perneger T, Bounameaux $\mathrm{H}$, et al. Clinical prediction rules for pulmonary embolism: a systematic review and meta-analysis. J Thromb Haemost. 2010;8(5):957-70. doi:10.1111/j.1538-7836.2010.03801.x.

18. Esposito R, Santoro C, Sorrentino R, Alcidi G, De Roberto AM, Santoro A, et al. The role of cardiovascular ultrasound in diagnosis and management of pulmonary embolism. Future Cardiol. 2017;13(5). doi:10.2217/fca2017-0037.

19. van BeekEJ, Reekers JA, Batchelor DA, Brandjes DP, Büller HR. Feasibility, safety and clinical utility of angiography in patients with suspected pulmonary embolism. Eur Radiol. 1996;6(4):415-9.

20. Konstantinides S, Torbicki A, Agnelli G, Danchin N, Fitzmaurice D, Galiè N, et al. [2014 ESC guidelines on the diagnosis and management of acute pulmonary embolism]. Kardiol Pol. 2014;72(11):997-1053. doi:10.5603/ KP.2014.0211. Polish.

21. Tomkowski WZ, Davidson BL, Wisniewska J, Malek G, Kober J, Kuca $P$, et al. Accuracy of compression ultrasound in screening for deep venous thrombosis in acutely ill medical patients. Thromb Haemost. 2007;97(2):191-4. doi:10.1160/TH06-10-0601.

22. Kearon C, Ginsberg JS, Hirsh J. The role of venous ultrasonography in the diagnosis of suspected deep venous thrombosis and pulmonary embolism. Ann Intern Med. 1998;129(12):1044-9. doi:10.7326/00034819-129-12-199812150-00009.

23. Weg JG, Froehlich JB. Ultrasonography of leg veins in patients suspected of having pulmonary embolism. Ann Intern Med. 1998;128(3):243; author reply 244-5.

24. Albayati MA, Grover SP, Saha P, Lwaleed BA, Modarai B, Smith A. Postsurgical inflammation as a causative mechanism of venous thromboembolism. Semin Thromb Hemost. 2015; 41 (6):615-20. doi:10.1055/s-0035-1556726.

25. Wakefield TW, Myers DD, Henke PK. Mechanisms of venous thrombosis and resolution. Arterioscler Thromb Vasc Biol. 2008;28(3):387-91. doi:10.1161/ATVBAHA.108.162289.

26. Saha P, Humphries J, Modarai B, Mattock K, Waltham M, Evans CE, et al. Leukocytes and the natural history of deep vein thrombosis: current concepts and future directions. Arterioscler Thromb Vasc Biol. 2011;31(3):506-12. doi:10.1161/ATVBAHA.110.213405.

27. White RH, Zhou H, Romano PS. Incidence of symptomatic venous thromboembolism after different elective or urgent surgical procedures. Thromb Haemost. 2003;90(3):446-55. doi:10.1160/TH03-03-0152.

28. Beksaç B, González Della Valle A, Salvati EA. Thromboembolic disease after total hip arthroplasty: who is at risk? Clin Orthop Relat Res. 2006;453:211-24. doi:10.1097/01.blo.0000238848.41670.41.

29. Geerts WH, Pineo GF, Heit JA, Bergqvist D, Lassen MR, Colwell CW, et al. Prevention of venous thromboembolism: the seventh ACCP conference on antithrombotic and thrombolytic therapy. Chest. 2004;126(3 Suppl):338S-400S. doi:10.1378/chest.126.3_suppl.338S. 
30. Heit JA, Silverstein MD, Mohr DN, Petterson TM, O'fallon WM, Melton LJ. Risk factors for deep vein thrombosis and pulmonary embolism: a population-based case-control study. Arch Intern Med. 2000;160(6):80915. doi:10.1001/archinte.160.6.809.

31. Wahl D, Guillemin F, De Maistre E, Perret C, Lecompte T, Thibaut G. Risk for venous thrombosis related to antiphospholipid antibodies in systemic lupus erythematosus - a meta-analysis. Lupus. 1997;6(5):46773. doi:10.1177/096120339700600510.

32. Weill-Engerer S, Meaume S, Lahlou A, Piette F, Saint-Jean O, Sachet A, et al. Risk factors for deep vein thrombosis in inpatients aged 65 and older: a case-control multicenter study. J Am Geriatr Soc. 2004;52(8):1299-304. doi:10.1111/j.1532-5415.2004.52359.x.

33. Gonzalez Della Valle A, Serota A, Sorriaux G, Go G, Sharrock N, Sculco T, et al. Venous thromboembolism is rare after total hip arthroplasty with a multimodal prophylaxis protocol. Clin Orthop Relat Res. 2006;443:14653. doi:10.1097/01.blo.0000201157.29325.f0.

34. Fisher B, Costantino JP, Wickerham DL, Redmond CK, Kavanah M, Cronin WM, et al. Tamoxifen for prevention of breast cancer: report of the national surgical adjuvant breast and bowel project P-1 study. J Natl Cancer Inst. 1998;90(18):1371-88. doi:10.1093/jnci/90.18.1371.

35. Cummings SR, Eckert S, Krueger KA, Grady D, PowlesTJ, Cauley JA, et al. The effect of raloxifene on risk of breast cancer in postmenopausal women: results from the MORE randomized trial. Jama. 1999;281 (23):2189-97. Erratum in: JAMA 1999;282(22):2124. doi:10.1001/jama.281.23.2189.

36. Kelly J, Rudd A, Lewis RR, Coshall C, Moody A, Hunt BJ. Venous thromboembolism after acute ischemic stroke: a prospective study using magnetic resonance direct thrombus imaging. Stroke. 2004;35(10):23205. doi:10.1161/01.STR.0000140741.13279.4f.

37. Prandoni P, Bilora F, Marchiori A, Bernardi E, Petrobelli F, Lensing AW, et al. An association between atherosclerosis and venous thrombosis. N Engl J Med. 2003;348(15):1435-41. doi:10.1056/NEJMoa022157.

38. Macaulay W, Westrich G, Sharrock N, Sculco TP, Jhon PH, Peterson $M G$, et al. Effect of pneumatic compression on fibrinolysis after total hip arthroplasty. Clin Orthop Relat Res. 2002;399(399):168-76. doi:10.1097/00003086-200206000-00020.

39. Mantilla CB, Horlocker TT, Schroeder DR, Berry DJ, Brown DL. Risk factors for clinically relevant pulmonary embolism and deep venous thrombosis in patients undergoing primary hip or knee arthroplasty. Anesthesiology. 2003;99(3):552-60; discussion 5A.

40. Movahed MR, Hashemzadeh M, Jamal MM. The prevalence of pulmonary embolism and pulmonary hypertension in patients with type II diabetes mellitus. Chest. 2005;128(5):3568-71. doi:10.1378/chest.128.5.3568.

41. Zareifar S, Cheriki S, Namdari M, Farahmandfar M, Jannati A. Pericardial effusion and atrial thrombosis: a rare complication of childhood leukemia. Iran J Pediatr. 2012;22(1):117-20.

42. Ho KM, Bham E, Pavey W. Incidence of venous thromboembolism and benefits and risks of thromboprophylaxis after cardiac surgery: a systematic review and meta-analysis. J Am Heart Assoc. 2015;4(10):e002652. doi:10.1161/JAHA.115.002652.

43. Falck-Ytter Y, Francis CW, Johanson NA, Curley C, Dahl OE, Schulman S, et al. Prevention of VTE in orthopedic surgery patients: antithrombotic therapy and prevention of thrombosis, 9th ed: American college of chest physicians evidence-based clinical practice guidelines. Chest. 2012;141(2 Suppl):e278S-e325S. doi:10.1378/chest.11-2404.

44. Vandvik PO, Lincoff AM, Gore JM, Gutterman DD, Sonnenberg FA, AlonsoCoello P, et al. Primary and secondary prevention of cardiovascular disease: antithrombotic therapy and prevention of thrombosis: American college of chest physicians evidence-based clinical practice guidelines. Chest. 2012;141(2 Suppl):e637S-e668S. Erratum in: Chest. 2012;141(4):1129. Dosage error in article text. doi:10.1378/chest.11-2306. 45. Kojuri J, Mahmoody Y, Sabegh BZ, Jannati M, Mahboodi A, Khalili A. Dose- related effect of aspirin on laboratory-defined Platelet aggregation and clinical outcome after coronary stenting. Cardiovasc Ther. 2010;28(3):14752. doi:10.1111/j.1755-5922.2010.00170.x.

46. Cohen AT, Imfeld S, Markham J, Granziera S. The use of aspirin for primary and secondary prevention in venous thromboembolism and other cardiovascular disorders. Thromb Res. 2015;135(2):217-25. doi:10.1016/j.thromres.2014.11.036.

47. Hawkins D. The role of oral direct thrombin inhibitors in the prophylaxis of venous thromboembolism. Pharmacotherapy. 2004;24(10 Pt 2):179S-183S. doi:10.1592/phco.24.15.179S.43158.

48. Eriksson BI, Kälebo P, Bergqvisty D, Dahl OE, Lindbratt S, Bylock A, et al. Ximelagatran and melagatran compared with dalteparin for prevention of venous thromboembolism after total hip or knee replacement: the METHRO II randomised trial. Lancet. 2002;360(9344):1441-7. doi:10.1016/ s0140-6736(02)11469-3.

49. Eriksson BI, Lassen MR. Duration of prophylaxis against venous thromboembolism with fondaparinux after hip fracture surgery: a multicenter, randomized, placebo-controlled, double-blind study. Arch Intern Med. 2003;163(11):1337-42. doi:10.1001/archinte.163.11.1337.

50. Steffen LM, Cushman M, Peacock JM, Heckbert SR, Jacobs DR $J$ r, Rosamond WD, et al. Metabolic syndrome and risk of venous thromboembolism: longitudinal investigation of thromboembolism etiology. J Thromb Haemost. 2009;7(5):746-51. doi:10.1111/j.15387836.2009.03295.x.

51. Fox EA, Kahn SR. The relationship between inflammation and venous thrombosis. Thromb Haemost. 2005;94(2):362-5. doi:10.1160/TH0504-0266.

52. Piazza G, Goldhaber SZ, Lessard DM, Goldberg RJ, Emery C, Spencer FA. Venous thromboembolism in patients with symptomatic atherosclerosis. Thromb Haemost. 2011;106(6):1095-102. doi:10.1160/TH11-07-0469.

53. Tafur AJ, Kalsi H, Wysokinski WE, McBane RD, Ashrani AA, Marks RS, et al. The association of active cancer with venous thromboembolism location: a population-based study. Mayo Clin Proc. 2011;86(1):25-30. doi: 10.4065/mcp.2010.0339.

54. Sweetland S, Green J, Liu B, de González AB, Canonico M, Reeves G, et al. Duration and magnitude of the postoperative risk of venous thromboembolism in middle aged women: prospective cohort study. BMJ. 2009;339:b4583. Erratum in: BMJ.2010;340:c417. doi: 10.1136/ bmj.b4583.

55. Blanco-Molina A, Rota LL, Di Micco P, Brenner B, Trujillo-Santos J, Ruiz-Gamietea A, et al. Venous thromboembolism during pregnancy, postpartum or during contraceptive use. Thromb Haemost. 2010;103(2):306-11. doi:10.1160/TH09-08-0559.

56. Greer IA. The special case of venous thromboembolism in pregnancy. Haemostasis. 1998;28 Suppl 3:22-34. doi:10.1159/000022402.

57. Greer IA. Thrombosis in pregnancy: maternal and fetal issues. Lancet. 1999;353(9160):1258-65. doi:10.1016/S0140-6736(98)10265-9.

58. Ambrosetti M, Salerno M, Zambelli M, Mastropasqua F, Tramarin $\mathrm{R}$, Pedretti RF. Deep vein thrombosis among patients entering cardiac rehabilitation after coronary artery bypass surgery. Chest. 2004;125(1):191-6. doi:10.1378/chest.125.1.191.

59. Goldhaber SZ, Hirsch DR, MacDougall RC, Polak JF, Creager MA, Cohn LH. Prevention of venous thrombosis after coronary artery bypass surgery (a randomized trial comparing two mechanical prophylaxis strategies). Am J Cardiol. 1995;76(14):993-6. doi:10.1016/S0002-9149(99)80282-3.

60. Reis SE, Polak JF, Hirsch DR, Cohn LH, Creager MA, Donovan BC, et al. Frequency of deep venous thrombosis in asymptomatic patients with coronary artery bypass grafts. Am Heart J. 1991;122(2):478-82. doi:10.1016/0002-8703(91)91004-7.

61. Pouplard C, May MA, lochmann S, Amiral J, Vissac AM, Marchand M, et al. Antibodies to platelet factor 4-heparin after cardiopulmonary 
bypass in patients anticoagulated with unfractionated heparin or a low-molecular-weight heparin: clinical implications for heparin-induced thrombocytopenia. Circulation. 1999;99(19):2530-6. doi:10.1161/01. CIR.99.19.2530.

62. Josa M, Siouffi SY, Silverman AB, Barsamian EM, Khuri SF, Sharma GV. Pulmonary embolism after cardiac surgery. J Am Coll Cardiol. 1993;21(4):990-6. doi:10.1016/0735-1097(93)90358-8.

63. Beck KS, Cho EK, Moon MH, Kim DY, Song H, Jung JI. Incidental pulmonary embolism after coronary artery bypass surgery: long-term clinical follow-up. AJR Am J Roentgenol. 2018;210(1):52-7. doi:/10.2214/ AJR.17.18186.

64. Viana VB, Melo ER, Terra-Filho M, Dallan LA, Gonzalez MM, Hajjar LA, et al. Frequency of deep vein thrombosis and/or pulmonary embolism after coronary artery bypass grafting investigation regardless of clinical suspicion. Am J Cardiol. 2017;119(2):237-42. doi:/10.1016/j. amjcard.2016.09.056.

65. Keenan CR, White RH. Age as a risk factor for venous thromboembolism after major surgery. Curr Opin Pulm Med. 2005;11(5):398-402. doi:10.1097/01.mcp.0000174246.15386.69.

66. White $\mathrm{RH}$, Zhou H, Gage BF. Effect of age on the incidence of venous thromboembolism after major surgery. J Thromb Haemost. 2004;2(8):1327-33. doi:10.1046/j.1538-7836.2004.00848.x.

67. Bucci C, Geerts WH, Sinclair A, Fremes SE. Comparison of the effectiveness and safety of low-molecular weight heparin versus unfractionated heparin anticoagulation after heart valve surgery. Am J Cardiol. 2011;107(4):591-4. doi:10.1016/j.amjcard.2010.10.020.

68. Song HK, Tibayan FA, Kahl EA, Sera VA, Slater MS, Deloughery TG, et al. Safety and efficacy of prothrombin complex concentrates for the treatment of coagulopathy after cardiac surgery. J Thorac Cardiovasc
Surg. 2014;147(3):1036-40. doi:10.1016/j.jtcvs.2013.11.020.

69. Close V, Purohit M, Tanos M, Hunter S. Should patients post-cardiac surgery be given low molecular weight heparin for deep vein thrombosis prophylaxis? Interact Cardiovasc Thorac Surg. 2006;5(5):6249. doi:10.1510/icvts.2006.137703.

70. Sarker SH, Miraj AK, Hossain MA, Aftabuddin M. Deep vein thrombosis in a post-coronary artery bypass grafting patient: successful conservative management. Mymensingh Med J. 2017;26(3):689-93.

71. Butt AJ, McCarthy T, Kelly IP, Glynn T, McCoy G. Sciatic nerve palsy secondary to postoperative haematoma in primary total hip replacement. J Bone Joint Surg Br. 2005;87(11):1465-7. doi:10.1302/0301620X.87B11.16736.

72. Ho KM, Chavan S. Prevalence of thrombocytosis in critically ill patients and its association with symptomatic acute pulmonary embolism. A multicentre registry study. Thromb Haemost. 2013;109(2):272-9. doi:10.1160/TH12-09-0658.

73. Pantely GA, Goodnight SH Jr, Rahimtoola SH, Harlan BJ, DeMots H, Calvin $\mathrm{L}$, et al. Failure of antiplatelet and anticoagulant therapy to improve patency of grafts after coronary-artery bypass: a controlled, randomized study. N Engl J Med. 1979;301(18):962-6. doi:10.1056/ NEJM197911013011803.

74. Cikirikcioglu M, Myers PO, Kalangos A. First do no harm: postoperative thromboprophylaxis following open heart surgery. Eur J Cardiothorac Surg. 2013;44(1):184. doi:10.1093/ejcts/ezs669.

75. Kulik A, Rassen JA, Myers J, Schneeweiss S, Gagne J, Polinski $J M$, et al. Comparative effectiveness of preventative therapy for venous thromboembolism after coronary artery bypass graft surgery. Circ Cardiovasc Interv. 2012;5(4):590-6. doi:10.1161/ CIRCINTERVENTIONS.112.968313. 